\title{
Water-Nitrogen Coupling Effect on Drip-Irrigated Dense Planting of Dwarf Jujube in an Extremely Arid Area
}

\author{
En Lin ${ }^{1,2}$, Hongguang Liu ${ }^{1,2, *}$, Xinlin $\mathrm{He}^{1,2}$, Xinxin $\mathrm{Li}^{1,2}$, Ping Gong ${ }^{1,2}$ and Ling $\mathrm{Li}^{1,2}$ \\ 1 College of Water Conservancy \& Architectural Engineering, Shihezi University, Shihezi, 832000, China; \\ linen2018@163.com (E.L.); hexinlin2002@163.com (X.H.); lixxen520@163.com (X.L.); \\ gongping0993@163.com (P.G.); june286647@163.com (L.L.) \\ 2 Xinjiang Production \& Construction Group Key Laboratory of Modern Water-Saving Irrigation, Shihezi, \\ 832000, China \\ * Correspondence: liuhongguang-521@163.com; Tel.: +86-0993-2057229
}

Received: 31 July 2019; Accepted: 17 September 2019; Published: 18 September 2019

check for updates

\begin{abstract}
Hami, Xinjiang, is located in an extremely arid region and jujube is the main economic crop. It is important to adopt dwarf and close-planting technology under drip irrigation and to optimize water and fertilizer management to improve jujube yield and quality. Local 12-year-old jujube trees were treated using two factors of irrigation and fertilization. Three irrigation amounts $(520,700$, and $880 \mathrm{~mm})$ and three fertilization levels $\left(248,318\right.$, and $\left.388 \mathrm{~kg} / \mathrm{hm}^{2}\right)$ were set up in plot experiments. The root system, yield, and quality of jujube were monitored under different irrigation and nitrogen application combinations. The effects on water use efficiency (WUE), nitrogen partial factor productivity (PNP), and economic benefit were analyzed. The water and fertilizer coupling effect of dwarf closely planted jujube was studied by combining multiple regression and spatial analyses. The yield, quality, economic benefits, WUE, and PNP of jujube were significantly affected by irrigation and fertilization. Multiple regression and spatial analyses showed that the highest yield was for irrigation of $700 \mathrm{~mm}$ and a nitrogen rate of $340 \mathrm{~kg} / \mathrm{hm}^{2}$. For the maximum net benefit, irrigation was $806 \mathrm{~mm}$ and nitrogen was $388 \mathrm{~kg} / \mathrm{hm}^{2}$; correspondingly, for the highest total sugar, values were $688 \mathrm{~mm}$ and $362 \mathrm{~kg} / \mathrm{hm}^{2}$; for vitamin C, they were $622 \mathrm{~mm}$ and $376 \mathrm{~kg} / \mathrm{hm}^{2}$; for PNP, they were $880 \mathrm{~mm}$ and $256.57 \mathrm{~kg} / \mathrm{hm}^{2}$; and for WUE, they were $520 \mathrm{~mm}$ and $388 \mathrm{~kg} / \mathrm{hm}^{2}$. A comprehensive evaluation of each index showed that the acceptable irrigation amount for yield, quality, WUE, and net benefit of $\geq 85 \%$ of the maximum value was $600-628 \mathrm{~mm}$, and the nitrogen application rate was $360-372 \mathrm{~kg} / \mathrm{hm}^{2}$. This study provides guidance for the scientific management of water and fertilizer in the drip irrigation and fertilization process of local jujube trees.
\end{abstract}

Keywords: extreme drought area; dwarf close-planting; drip irrigation; jujube; water-nitrogen coupling

\section{Introduction}

Xinjiang jujube planting area is 54,400 ha, accounting for one-third of China's total jujube area [1,2]. In Hami, Xinjiang, the jujube area already accounts for $75 \%$ of the total fruit planted area and jujube is the main source of income for local farmers. South Xinjiang is short of water resources and this severely limits development of the jujube industry. More efficient water-saving and precision fertilization technologies must be developed to improve economic benefits [3]. Drip irrigation is an efficient water-saving irrigation technology, and can accurately deliver water and nutrients needed by crops to the root zone, thus saving water, increasing production, and saving labor [4]. Because of the use 
of drip irrigation, the jujube planting mode in Xinjiang has changed to dwarf close-planting mode, and the new irrigation technology and planting mode also affect water and fertilizer utilization.

Many scholars have studied the effects of water and fertilizer use on the growth index, physiological changes, yield, and quality of drip irrigation for fruit trees in Xinjiang [5-9]. They have usually used multiple regression methods to determine the optimum ratio of water and nitrogen for each index of jujube trees. In these cases, regression equations with water and nitrogen as independent variables and each single index as a dependent variable are established, and the optimal combination of irrigation and nitrogen application is obtained by solving each equation [9-11]. However, this kind of research mainly focuses on the influence of single factors, such as irrigation nitrogen application and planting density, or the influence of water and nitrogen combinations on jujube growth. It is difficult to optimize several indexes such as jujube yield, quality, and economic benefits in a single treatment in actual agricultural management. A spatial analysis method was used to horizontally project the three-dimensional curved surface obtained by the binary quadratic regression equation of each index to find the overlapping areas of the acceptable areas of each index [12-16]. This can simultaneously provide the optimal water and nitrogen combination range satisfying each index, and has wide application. Thompson et al. [12-15] used this method to evaluate the agronomic, environmental, and economic benefits for cauliflower and tomato, and obtained water and nitrogen ranges corresponding to the overlapping region of each index's acceptable region, which provides better operability.

On the basis of multiple regression analysis of various indexes of jujube, this paper provides an optimal combination of water and nitrogen for jujube yield, quality, economic benefit, and water and nitrogen utilization efficiencies. This gives feasible irrigation and nitrogen application intervals for each index from the perspective of high-efficiency water and nitrogen utilization, high yield, high quality, and high benefit, combined with the spatial analysis method. This provides a scientific basis for local jujube irrigation and nitrogen application.

\section{Materials and Methods}

\subsection{Experimental Site Description}

In 2015 and 2016, Hongxing, in which Hami jujube has been grown for many years by the 13th Division of Xinjiang (Figure 1) Production and Construction Corps, was selected to do one horticulture in two fields, four buckets, and one ridge. The effects of water-nitrogen coupling on jujube yield, quality, water use efficiency (WUE), nitrogen partial productivity (PNP), and economic benefits were studied in 2015 and 2016, and the effects of water-nitrogen coupling on the root system were increased on the basis of the original detection index in 2016.

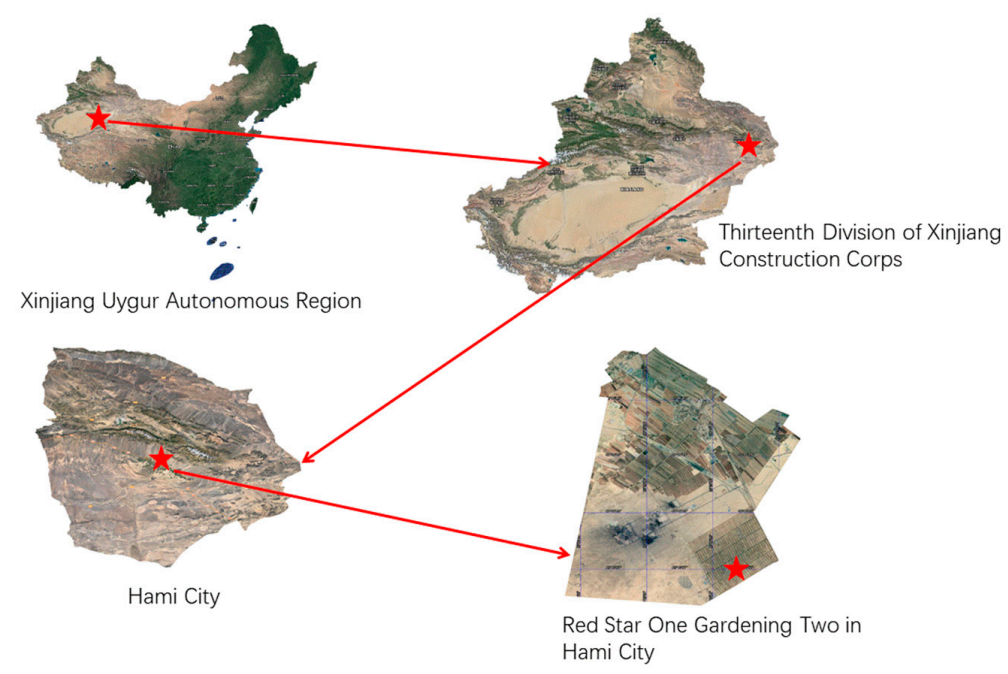

Figure 1. The experimental zone schematic geographical position. 
The altitude of the test area is $833 \mathrm{~m}$, and it is located at $42^{\circ} 32^{\prime} 23^{\prime \prime} \mathrm{N}$ and $94^{\circ} 11^{\prime} 08^{\prime \prime} \mathrm{E}$. This area is a typical extremely arid area with a temperate continental climate, and annual average precipitation of less than $50 \mathrm{~mm}$ over many years. During the whole growth period of jujube, the total rainfall was only about $30 \mathrm{~mm}$, representing less than $10 \%$ of annual average evaporation. The annual sunshine duration is $3360 \mathrm{~h}$, the accumulated temperature greater than $10^{\circ} \mathrm{C}$ is $4260^{\circ} \mathrm{C}$, and the frost-free period is about 160 days. The groundwater depth in the test area is below $15 \mathrm{~m}$, and so the influence of groundwater recharge on jujube planting was not considered. The hydrochemical type is $\mathrm{SO}_{4} \cdot \mathrm{HCO}_{3}(\mathrm{CL}) \sim \mathrm{Na} \cdot \mathrm{Ca}$. The total soluble solids content is about $0.3-4 \mathrm{~g} / \mathrm{L}$. The $\mathrm{PH}$ value is $7.8-8.2$. The main growth area of jujube roots is soil above $100 \mathrm{~cm}$ depth, and the soil is mainly sandy soil with poor water and fertilizer conservation. Every spring, farmyard manure and a small amount of chemical fertilizer is applied to the soil layer above $40 \mathrm{~cm}$ depth as the planting base fertilizer. The average bulk density of the soil in the test area was $1.5 \mathrm{~g} / \mathrm{cm}^{3}$, and the field water holding rate was $16 \%$ (mass water content).

\subsection{Experimental Treatments and Design}

The jujube trees in the experimental area were 13 years of age, average tree height was $1.65 \mathrm{~m}$, and row spacing was $5 \mathrm{~m} \times 2 \mathrm{~m}$ (Figure 2). The experiment included three fertilization levels and three irrigation levels. The experiment used a two-factor completely randomized block design, with a total of nine treatments and three repetitions of each treatment (Table 1). Each processing cell was three consecutive rows, each row being $30 \mathrm{~m}$ in length (Figure 2). In the experiment, a single-wing labyrinth drip irrigation belt was used. The designed pressure head flow rate of the dripper was $3.2 \mathrm{~L} / \mathrm{h}$, and the distance between drippers was $30 \mathrm{~cm}$. The drip irrigation belts were arranged in a row and two pipes (Figure 2), the interval between the drip irrigation belts was $120 \mathrm{~cm}$, and each drip irrigation belt was $60 \mathrm{~cm}$ away from the trunk. Each treatment was irrigated separately, and a ball valve was used as the irrigation switch to control the irrigation amount with the water meter. The jujube tree growth is divided into the following four stages: sprouting new shoots (15 May to 20 June), flowering (21 June to 20 July), fruit inflation (21 July to 15 September), and maturity (16 September to 30 October) stages (Table 2).

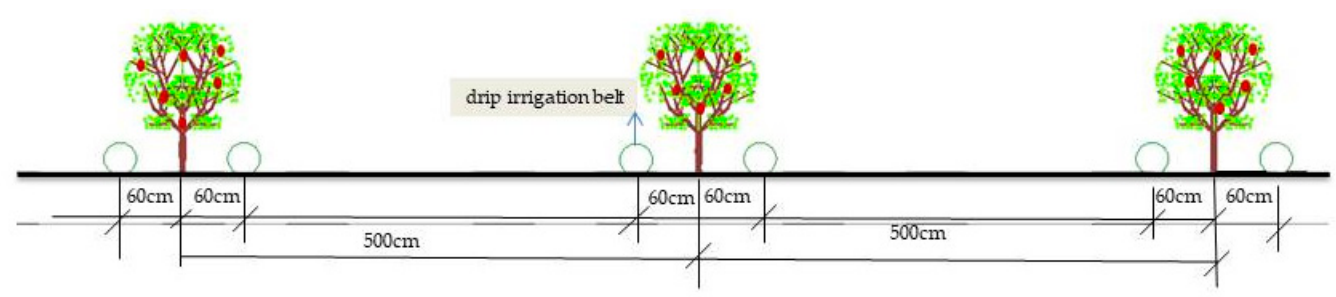

(a)

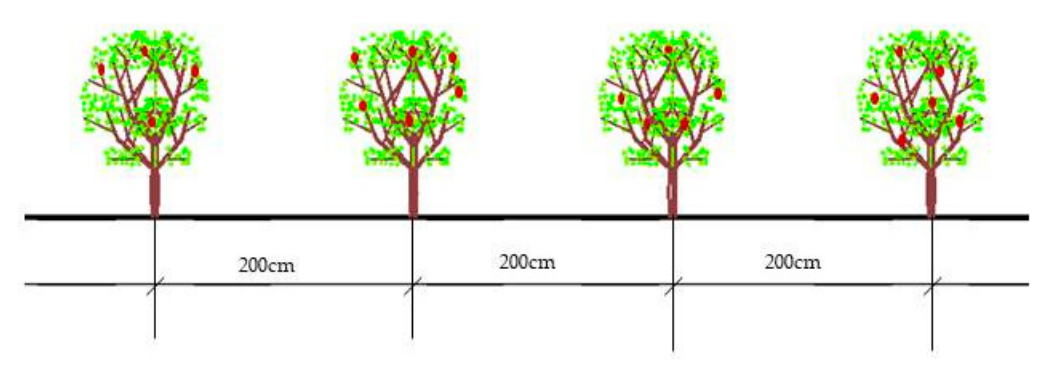

(b)

Figure 2. Cont. 


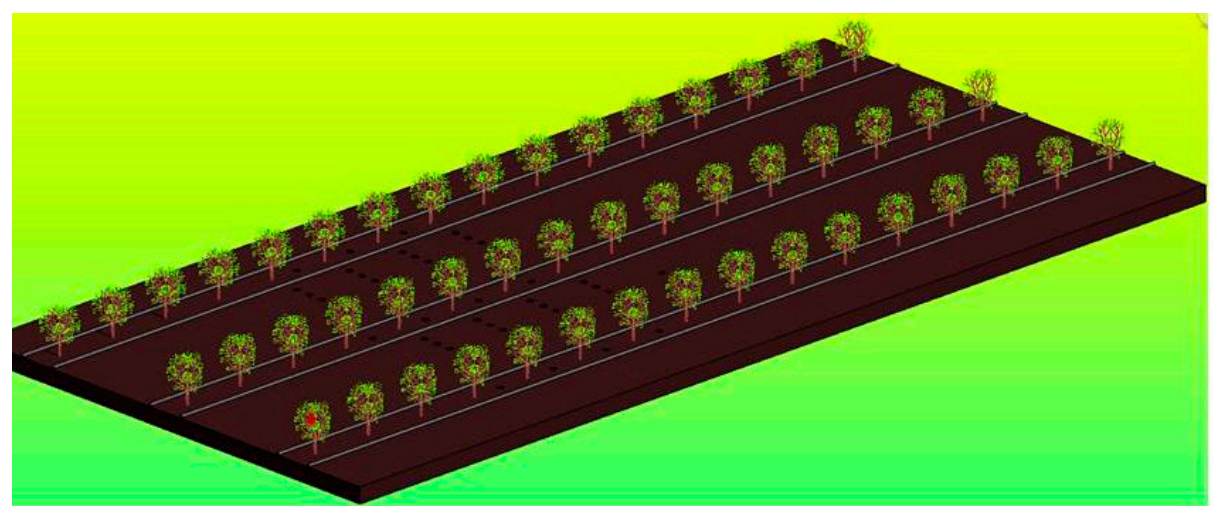

(c)

Figure 2. Jujube row spacing in Xinjiang (a); jujube plant spacing in Xinjiang (b); jujube planting model in Xinjiang (c).

Table 1. Experimental design of irrigation amount and nitrogen rate in full growth period in Xinjiang.

\begin{tabular}{|c|c|c|}
\hline Treatment & Irrigation Amount (mm) & Nitrogen Rate $\left(\mathrm{kg} / \mathrm{hm}^{2}\right)$ \\
\hline W1F1 & 520 & 248 \\
\hline W1F2 & 520 & 318 \\
\hline W1F3 & 520 & 388 \\
\hline W2F1 & 700 & 248 \\
\hline W2F2 & 700 & 318 \\
\hline W2F3 & 700 & 388 \\
\hline W3F1 & 880 & 248 \\
\hline W3F2 & 880 & 318 \\
\hline W3F3 & 880 & 388 \\
\hline
\end{tabular}

Table 2. Irrigation amount on the different irrigation treatments applied to jujube trees in Xinjiang.

\begin{tabular}{|c|c|c|c|c|c|c|c|}
\hline \multirow{2}{*}{ Item } & \multirow{2}{*}{ Irrigation Date } & \multicolumn{3}{|c|}{$\begin{array}{l}\text { Irrigation Amount } \\
(\mathrm{mm})\end{array}$} & \multicolumn{3}{|c|}{$\begin{array}{c}\text { Nitrogen Rate } \\
\left(\mathrm{kg} / \mathrm{hm}^{2}\right)\end{array}$} \\
\hline & & W1 & W2 & W3 & F1 & F2 & F3 \\
\hline \multirow{4}{*}{$\begin{array}{c}\text { Sprouting new } \\
\text { shoots stage (15 May-20 June) }\end{array}$} & 24 May & 35 & 49 & 65 & 23 & 28 & 36 \\
\hline & 2 June & 42 & 55 & 73 & 20 & 24 & 32 \\
\hline & 11 June & 45 & 60 & 68 & 19 & 26 & 30 \\
\hline & 20 June & 38 & 58 & 69 & 22 & 28 & 31 \\
\hline \multirow{4}{*}{ flowering stage (21 June-20 July) } & 29 June & 48 & 57 & 65 & 21 & 25 & 32 \\
\hline & 8 July & 40 & 50 & 68 & 20 & 28 & 36 \\
\hline & 15 July & 36 & 50 & 67 & 22 & 26 & 34 \\
\hline & 20 July & 36 & 55 & 70 & 21 & 27 & 29 \\
\hline \multirow{4}{*}{$\begin{array}{l}\text { fruit inflation stage } \\
\text { (21 July-15 September) }\end{array}$} & 29 July & 35 & 53 & 65 & 25 & 28 & 34 \\
\hline & 15 August & 45 & 58 & 74 & 19 & 25 & 32 \\
\hline & 25 August & 40 & 50 & 67 & 17 & 26 & 30 \\
\hline & 10 September & 40 & 55 & 69 & 19 & 27 & 32 \\
\hline $\begin{array}{c}\text { maturity stage } \\
\text { (16 September-30 October) }\end{array}$ & 20 September & 40 & 50 & 60 & 0 & 0 & 0 \\
\hline Total & & 520 & 700 & 880 & 248 & 318 & 388 \\
\hline
\end{tabular}




\subsection{Measurements}

\subsubsection{Determination of Root Length Density and Root Weight Density of Jujube}

Roots were collected after jujube harvest. The root extraction equipment was a percussion drill (drill bit diameter $10 \mathrm{~cm}$ ) used for a sampling depth of $90 \mathrm{~cm}$, with one sample taken every $10 \mathrm{~cm}$ in depth. These were labeled and stored in a self-sealing bag, and root screening was carried out in the laboratory. These samples' distances between rows were 100, 150, 200, and $250 \mathrm{~cm}$ from the trunk, respectively (Figure 3). The sample distance between trees was 0 and $100 \mathrm{~cm}$ from the trunk (Figure 3). The soil and root samples were washed by clean water indoors, and then roots were spread neatly on $\mathrm{A} 3$ white paper marked with $30 \mathrm{~cm}$ long black line, and photos were taken with a digital camera. Root length density was calculated using Raster2 vector analysis software for vectorization and Excel for length conversion according to the proportion relation [17]. The photographed root system was put into a craft paper envelope, which was dried and of known quality, and was placed in an oven and dried to constant weight at $105^{\circ} \mathrm{C}$. It was then weighed to thereby calculate root weight density. The root data of these sample points represent the eigenvalue of the root system.

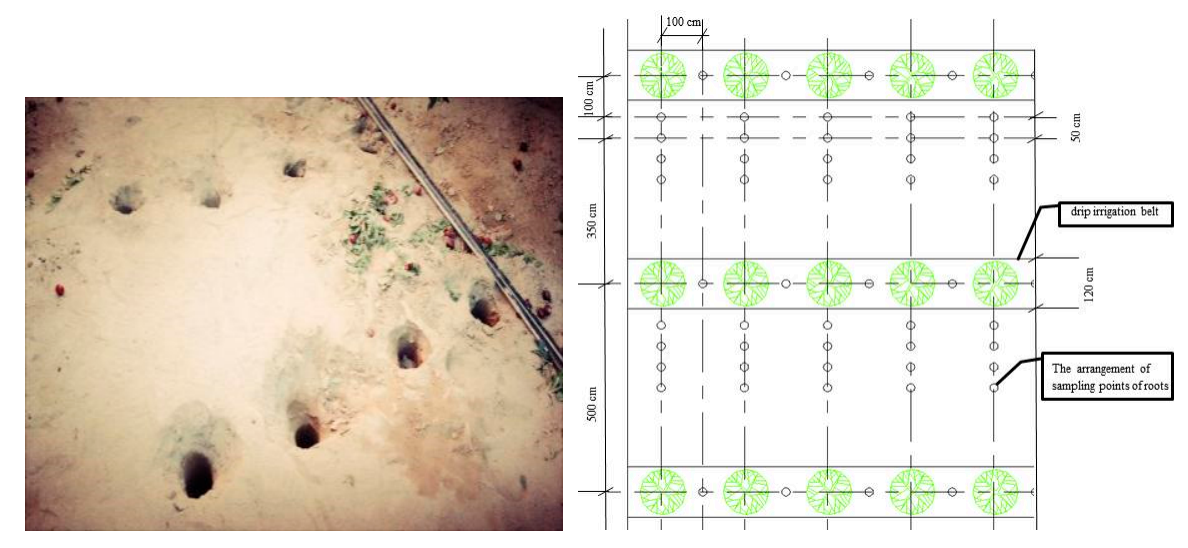

Figure 3. The arrangement of sampling points of roots in Xinjiang.

\subsubsection{Yield Determination}

When the jujube was ripe, it was picked according to plot. Five jujube trees were sampled for each treatment, and 20 jujube fruits were randomly taken from each tree to weigh 100 fresh fruits. The average value was taken, and this was equivalent to yield per hectare.

\subsubsection{Quality Determination}

Total sugar was determined by Fihrin method and vitamin $\mathrm{C}$ was determined by 2,6-dichloroindophenol titration method [18].

Calculation of WUE:

$$
\mathrm{WUE}=\mathrm{Y} / \mathrm{ET},
$$

where $\mathrm{Y}$ is the yield of jujube tree and ET is the water consumption.

$$
\mathrm{ET}=\mathrm{P}+\mathrm{U}+\mathrm{I}-\mathrm{F}-\mathrm{R}-\Delta \mathrm{W},
$$

where $\mathrm{P}$ is precipitation, $\mathrm{U}$ is groundwater recharge, $\mathrm{I}$ is irrigation amount, $\mathrm{F}$ is deep seepage, $\mathrm{R}$ is runoff, and $\Delta \mathrm{W}$ is the change of soil moisture in $0-100 \mathrm{~cm}$ between the beginning and end of the experiment (all in $\mathrm{mm}$ ). According to the actual situation during the test, groundwater recharge, deep seepage, and runoff were ignored.

$$
\Delta \mathrm{W}=10 \sum H_{i}\left(\theta_{i 1}-\theta_{i 2}\right) \gamma_{i},
$$


where $H_{i}$ is the soil thickness of the i-th layer, $\gamma_{i}$ is the soil dry bulk density of the i-th layer, and $\theta_{i 1}-\theta_{i 2}$ is the water content at the beginning and end of the soil calculation period of the $i$-th layer [19].

\subsubsection{Nitrogen Partial Productivity (PNP)}

PNP was calculated by the following formula:

$$
\mathrm{PNP}=\mathrm{Y} / \mathrm{F}
$$

where $\mathrm{Y}$ is red jujube yield and $\mathrm{F}$ is nitrogen application rate (both $\left.\mathrm{kg} / \mathrm{hm}^{2}\right)$ [20].

\subsubsection{Economic Benefit}

Economic benefit was determined using the following equation:

$$
\mathrm{E}=\mathrm{G}-\mathrm{M}-\mathrm{N}-\mathrm{I}
$$

where $\mathrm{E}$ is net income, $\mathrm{G}$ is economic income, $\mathrm{M}$ is water and nitrogen input, $\mathrm{N}$ is red jujube labor cost, and I is other input (all $\mathrm{RMB} / \mathrm{hm}^{2}$ ); The unit price of red jujube is $7.9 \mathrm{RMB}$ and other expenses are 17,400 RMB.

\subsection{Data Analysis}

Microsoft Excel 2010 and Matlab 2018 were used for data calculation, SPSS 16.0 for variance analysis, and Origin 8.0 for drawing.

\section{Results and Analysis}

\subsection{Effects of Water and Fertilizer Treatment on Jujube Root Length and Weight Densities}

The root weight and length densities at each sampling point were added separately to represent the total root characteristic value of the root system, and the effect of water and nitrogen coupling on root growth was analyzed (Table 3).

\begin{tabular}{|c|c|c|c|}
\hline Irrigation Level & $\begin{array}{c}\text { Nitrogen Application } \\
\text { Level }\end{array}$ & $\begin{array}{l}\text { Root Length Density } \\
\qquad\left(\mathrm{cm} / \mathrm{cm}^{3}\right)\end{array}$ & $\begin{array}{l}\text { Root Weight Density } \\
\qquad\left(\mathrm{g} / \mathrm{cm}^{3}\right)\end{array}$ \\
\hline \multirow{4}{*}{ W1 } & F1 & $0.502 \mathrm{e}$ & $0.411 \mathrm{f}$ \\
\hline & $\mathrm{F} 2$ & $0.606 \mathrm{e}$ & $0.561 \mathrm{e}$ \\
\hline & F3 & $0.775 \mathrm{~d}$ & $0.671 \mathrm{de}$ \\
\hline & $\mathrm{F} 1$ & $0.754 \mathrm{~d}$ & $0.701 \mathrm{~d}$ \\
\hline \multirow[t]{2}{*}{ W2 } & $\mathrm{F} 2$ & $1.174 \mathrm{ab}$ & $0.849 \mathrm{~b}$ \\
\hline & F3 & $1.261 \mathrm{a}$ & $0.947 a$ \\
\hline \multirow{3}{*}{ W3 } & $\mathrm{F} 1$ & $0.803 c$ & $0.744 \mathrm{~cd}$ \\
\hline & $\mathrm{F} 2$ & $0.928 b$ & $0.824 b c$ \\
\hline & F3 & $1.096 \mathrm{ab}$ & $0.866 \mathrm{ab}$ \\
\hline \multicolumn{2}{|c|}{ Irrigation } & * & * \\
\hline \multicolumn{2}{|c|}{ Nitrogen application } & $* *$ & $* *$ \\
\hline \multicolumn{2}{|c|}{ Irrigation $\times$ nitrogen application } & $* *$ & $* *$ \\
\hline
\end{tabular}

Table 3. Effect of water and nitrogen treatments on the root system.

Note: ${ }^{*}$ means a significant difference $(p<0.05) ;{ }^{* *}$ means a very significant difference $(p<0.01)$; ns means no significant difference $(p>0.05)$.

Root length and weight densities were very significantly affected by the interaction of irrigation and nitrogen application $(p<0.01)$ (Table 3). Irrigation had a significant effect on root length and weight densities. Under the same irrigation level, the root length density increased with the increase in nitrogen application rate. At medium (W2) and high irrigation (W3) levels, there was no significant 
difference in root length density between the medium nitrogen (F2) and high nitrogen (F3) treatments, but the values were significantly higher than those of the other treatments (Table 3). At low irrigation (W1) levels, there was no significant difference among treatments except for high nitrogen treatment (F3). The root weight of high nitrogen (F3) was significantly higher than that of the other treatments at the medium irrigation (W2) levels. There was no significant difference in root weight density between the low nitrogen (F1), medium nitrogen (F2), and high nitrogen (F3) treatments at high irrigation (W3).

\subsection{Effect of Water-Nitrogen Coupling on Jujube Yield and Quality}

The water-nitrogen interaction had a significant effect on each quality index level $(p<0.05$; Table 4). At medium and high irrigation levels, there was a significant difference in single fruit weight under the low nitrogen (F1), medium nitrogen (F2), and high nitrogen (F3) treatments. Under the same irrigation condition, yield was significantly higher for the high nitrogen (F3) than the low nitrogen (F1) and medium nitrogen (F2) treatments $(p<0.05)$. Vitamin $C$ was significantly higher in the high nitrogen (F3) than the low nitrogen (F1) treatment $(p<0.05)$ (except for W3), and initially increased and then decreased with the increase in the nitrogen application rate. There was no significant effect on total sugar. Under the same nitrogen application condition, the change trends for yield, total sugar, and vitamin $\mathrm{C}$ were the same, with an initial increase and then decrease with the increase in irrigation amount. In general, the W2F3 treatment had the highest yield $\left(8868 \mathrm{~kg} / \mathrm{hm}^{2}\right)$ and total sugar $(73.13 \mathrm{~g} / 100 \mathrm{~g})$, while vitamin C was highest for W2F2 (120.75 mg/100 g), but did not significantly differ from that for W2F3 $(p<0.05)$.

Table 4. Output of jujube for water and nitrogen treatments.

\begin{tabular}{|c|c|c|c|c|c|}
\hline $\begin{array}{l}\text { Irrigation } \\
\text { Level }\end{array}$ & $\begin{array}{c}\text { Nitrogen } \\
\text { Application Level }\end{array}$ & $\begin{array}{l}\text { Single Fruit } \\
\text { Weight/(g) }\end{array}$ & Yield $\left(\mathrm{kg} / \mathrm{hm}^{2}\right)$ & $\begin{array}{l}\text { Total Sugar } \\
(\mathrm{g} / \mathbf{1 0 0} \mathrm{g})\end{array}$ & $\begin{array}{l}\text { Vitamin C } \\
(\mathrm{mg} / \mathbf{1 0 0} \mathrm{g})\end{array}$ \\
\hline \multirow{4}{*}{ W1 } & F1 & $8.71 \mathrm{e}$ & $6972 d$ & $68.18 \mathrm{~cd}$ & $110.14 \mathrm{e}$ \\
\hline & $\mathrm{F} 2$ & $8.90 \mathrm{~d}$ & $7135 d$ & $68.21 \mathrm{~cd}$ & $114.75 \mathrm{~cd}$ \\
\hline & F3 & $9.23 b c$ & $7262 \mathrm{~cd}$ & $68.72 \mathrm{bcd}$ & 113.31d \\
\hline & $\mathrm{F} 1$ & $9.00 \mathrm{~cd}$ & $7865 c$ & $66.83 \mathrm{~d}$ & $116.51 b c$ \\
\hline \multirow[t]{3}{*}{ W2 } & $\mathrm{F} 2$ & $9.35 b$ & $8176 b$ & $72.68 \mathrm{a}$ & $118.27 \mathrm{~b}$ \\
\hline & F3 & $10.19 \mathrm{a}$ & $8868 \mathrm{a}$ & $73.13 a$ & $120.75 a$ \\
\hline & $\mathrm{F} 1$ & $8.96 \mathrm{~d}$ & $8010 \mathrm{bc}$ & $70.31 \mathrm{abc}$ & $117.25 b$ \\
\hline \multirow[t]{2}{*}{ W3 } & $\mathrm{F} 2$ & $9.08 c$ & $8118 b c$ & $72.24 \mathrm{abc}$ & $118.49 \mathrm{~b}$ \\
\hline & F3 & $9.87 \mathrm{ab}$ & $8760 a$ & 71.64ab & $116.45 b c$ \\
\hline \multicolumn{2}{|c|}{ Irrigation } & $*$ & ns & ns & ns \\
\hline \multicolumn{2}{|c|}{ Nitrogen application } & $* *$ & * & * & ns \\
\hline \multicolumn{2}{|c|}{ Irrigation $\times$ nitrogen application } & * & $*$ & * & $*$ \\
\hline
\end{tabular}

The economic benefits of jujube under different water and fertilizer treatments did not significantly differ from those under single irrigation and nitrogen application treatments (Table 5). The economic benefit of jujube was $31,883.8 \mathrm{RMB} / \mathrm{hm}^{2}$ for W1F1 and $44,489.0 \mathrm{RMB} / \mathrm{hm}^{2}$ for W2F3. Generally, the yield, quality, and economic benefit of jujube were highest for W2F3 treatment. 
Table 5. Income and expenditure for jujube for water and nitrogen treatments.

\begin{tabular}{|c|c|c|c|c|c|}
\hline $\begin{array}{l}\text { Irrigation } \\
\text { Level }\end{array}$ & $\begin{array}{c}\text { Nitrogen } \\
\text { Application Level }\end{array}$ & $\begin{array}{l}\text { Economic Income } \\
\left(\mathrm{RMB} / \mathrm{hm}^{2}\right)\end{array}$ & $\begin{array}{l}\text { Water and Nitrogen } \\
\text { Input }\left(\mathrm{RMB} / \mathrm{hm}^{2}\right)\end{array}$ & $\begin{array}{c}\text { Other } \\
\left(\mathrm{RMB} / \mathrm{hm}^{2}\right)\end{array}$ & $\begin{array}{l}\text { Net Benefit } \\
\left(\mathrm{RMB} / \mathrm{hm}^{2}\right)\end{array}$ \\
\hline \multirow{4}{*}{ W1 } & $\mathrm{F} 1$ & $47,178.8$ & 2522 & 17400 & $28,256.92$ \\
\hline & $\mathrm{F} 2$ & $48,466.5 \mathrm{~d}$ & 2647 & 17400 & $32,438.5 \mathrm{ef}$ \\
\hline & F3 & $50,259.8 \mathrm{~cd}$ & 2771 & 17400 & $30,088.46 \mathrm{e}$ \\
\hline & $\mathrm{F} 1$ & $54,233.5 c$ & 3242 & 17400 & $33,591.22 \mathrm{~d}$ \\
\hline \multirow[t]{3}{*}{ W2 } & $\mathrm{F} 2$ & $56,690.4 b$ & 3367 & 17400 & $35,923.39 c$ \\
\hline & F3 & $62,157.2 \mathrm{a}$ & 3492 & 17400 & $41,265.46 a$ \\
\hline & $\mathrm{F} 1$ & $61,699 \mathrm{bc}$ & 3962 & 17400 & $40,336.36 \mathrm{~cd}$ \\
\hline \multirow[t]{2}{*}{ W3 } & $\mathrm{F} 2$ & $56,232.2 b c$ & 4087 & 17400 & $34,744.83 c$ \\
\hline & F3 & $61,304 a$ & 4212 & 17400 & $39,691.91 b$ \\
\hline \multicolumn{2}{|c|}{ Irrigation } & ns & I & I & ns \\
\hline \multicolumn{2}{|c|}{ Nitrogen application } & ns & 1 & / & ns \\
\hline \multicolumn{2}{|c|}{ Irrigation $\times$ nitrogen application } & * & / & 1 & $*$ \\
\hline
\end{tabular}

Note: * means a significant difference $(p<0.05) ;{ }^{* *}$ means a very significant difference $(p<0.01)$; ns means no significant difference $(p>0.05)$.

\subsection{Effects of Water-Nitrogen Coupling on WUE and PNP of Jujube}

WUE and PNP are the economic yield of crops produced by unit water consumption and nitrogen application rate of crops, which reflect the absorption and utilization process of water by crops and the investment benefit of fertilization, respectively. The irrigation and nitrogen treatments significantly affected jujube WUE and PNP (except for W2F1); WUE ranged between 0.60 and $0.94 \mathrm{~kg} / \mathrm{m}^{3}$, and PNP was $18.30-35.75 \mathrm{~kg} / \mathrm{kg}$. The maximum WUE value was for W1F3 treatment $\left(0.94 \mathrm{~kg} / \mathrm{m}^{3}\right)$ and the maximum for PNP was for W3F1 treatment $(35.75 \mathrm{~kg} / \mathrm{kg})$. Under the same irrigation condition, WUE first decreased and then increased with the increase of the nitrogen application rate under low irrigation (W1) and high irrigation (W3). However, for medium irrigation (W2), the WUE increased with the increase of fertilization amount. Under the same irrigation condition, PNP decreased with the increase in nitrogen application rate. Under the same nitrogen application conditions, low nitrogen (F1) and high nitrogen (F3) increased with the increase in irrigation amount. However, under the medium nitrogen (F2) condition, PNP initially decreased and then increased. Low water and high fertilizer were beneficial to improved WUE, and high water and low fertilizer were beneficial to improved PNP (Figure 4).
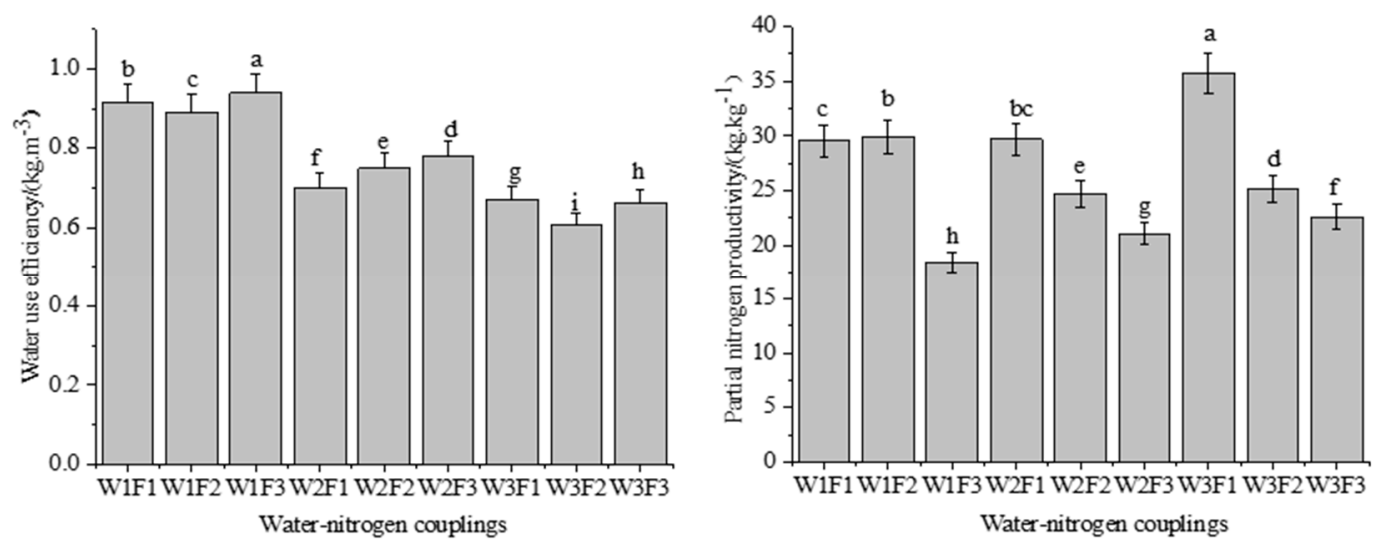

Figure 4. Effects of water-nitrogen coupling on water use efficiency and fertilizer partial productivity of jujube trees. Note: different lower-case letters indicate a significant difference between treatments $(p<0.05)$. 


\subsection{Correlation Analysis Between Root System and Yield}

The root system directly affects the absorption of nutrients by jujube trees, and thus affects yield. Reasonable irrigation and fertilization can promote the growth and development of the root system and expand the nutrient absorption space, and are conducive to yield increase of jujube trees. The root weight densities and the root length densities of jujube trees showed significant linear relationships with jujube trees yield. With good root growth, jujube yield increased significantly (Figure 5).
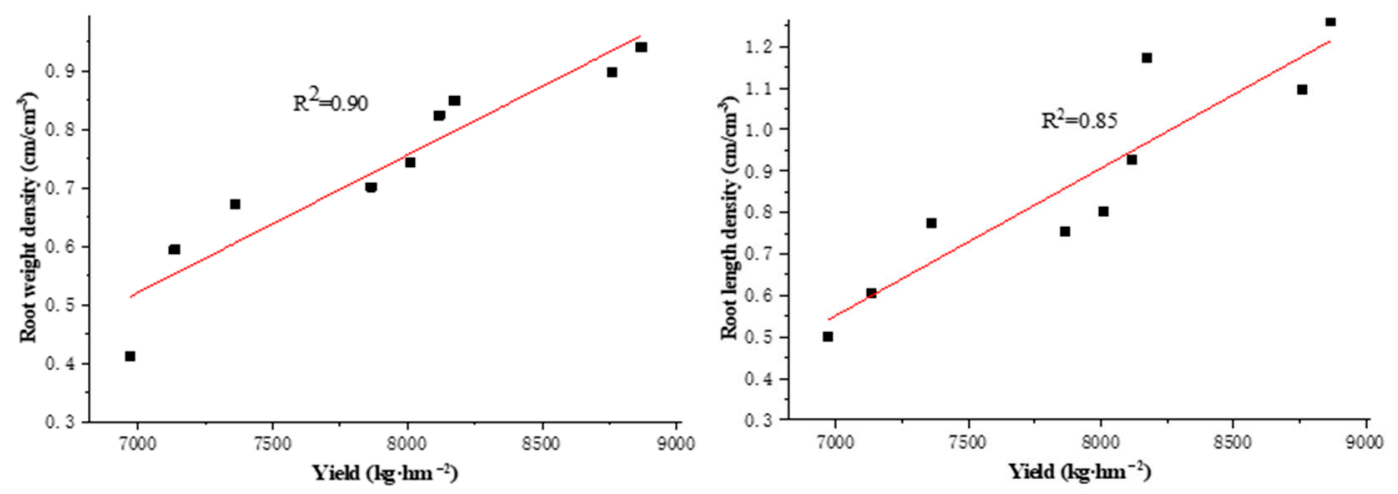

Figure 5. The relationship between yield and root weight density and root length density.

3.5. Relationship between Water and Fertilizer Input and Yield, Economic Benefit, Quality, PNP, and WUE of Jujube

A regression analysis was conducted with water and nitrogen input as independent variables and yield, net benefit, total sugar, and vitamin $C$ as respective dependent variables. The effects of water and fertilizer input on the dependent variables were significant, and the coefficient of determination exceeded 0.90 (Table 6). Setting the upper and lower limits of irrigation amount as low irrigation (W1) and high irrigation (W3), and the upper and lower limits of nitrogen application as low nitrogen (F1) and high nitrogen (F3), the maximum values of each equation in Table 6 below were obtained by solving the extremum problem using MATLAB, and the irrigation amount and nitrogen rate at the maximum value were obtained.

Table 6. Regression model of water and fertilizer input and jujube yield, economic benefit, quality, partial factor productivity (PNP), and water use efficiency (WUE).

\begin{tabular}{cccc}
\hline Output Variables & Regression Equation & $\boldsymbol{R}^{2}$ & $p$ \\
\hline Yield & $\mathrm{Y} 1=-0.0178 \mathrm{~W}^{2}+0.033 \mathrm{~F}^{2}+7.140 \times 10^{-5} \mathrm{WF}+25.819 \mathrm{~W}-21.076 \mathrm{~F}+589.293$ & 0.978 & $<0.05$ \\
Net benefit & $\mathrm{Y} 2=-0.102 \mathrm{~W}^{2}+0.512 \mathrm{~F}^{2}+0.49 \times 10^{-5} \mathrm{WF}+185.74 \mathrm{~W}-270.173 \mathrm{~F}+769.47$ & 0.977 & $<0.05$ \\
Total sugar & $\mathrm{Y} 3=-6.16 \times 10^{-5} \mathrm{~W}^{2}-1.51 \times 10^{-5} \mathrm{~F}^{2}+1.567 \times 10^{-6} \mathrm{WF}+0.0897 \mathrm{~W}+0.0976 \mathrm{~F}+20.561$ & 0.906 & $<0.05$ \\
Vitamin C & $\mathrm{Y} 4=-0.15 \times 10^{-4} \mathrm{~W}^{2}+3.12 \times 10^{-5} \mathrm{~F}^{2}+3.03 \times 10^{-5} \mathrm{WF}+0.021 \mathrm{~W}-0.029 \mathrm{~F}+10.452$ & 0.947 & $<0.05$ \\
PNP & $\mathrm{Y} 5=3.367 \times 10^{-7} \mathrm{~W}^{2}+1.27 \times 10^{-5} \mathrm{~F}^{2}-1.143 \times 10^{-6} \mathrm{WF}+2.465 \times 10^{-4} \mathrm{~W}-9.45 \times 10^{-5} \mathrm{~F}+2.304$ & 0.965 & $<0.05$ \\
WUE & $\mathrm{Y} 6=1.242 \times 10^{-6} \mathrm{~W}^{2}+6.48 \times 10^{-6} \mathrm{~F}^{2}+3.59 \times 10^{-7} \mathrm{WF}-2.64 \times 10^{-5} \mathrm{~W}-4.26 \times 10^{-5} \mathrm{~F}+2.632$ & 0.959 & $<0.05$ \\
\hline
\end{tabular}

Note: W, F, R ${ }^{2}$, and P represent irrigation amount, nitrogen application amount, coefficient of determination, and statistical significance value, respectively.

The maximum yield occurred for an irrigation amount of $700 \mathrm{~mm}$ and nitrogen rate of $340 \mathrm{~kg} / \mathrm{hm}^{2}$ correspondingly, the greatest net benefit was for $745 \mathrm{~mm}$ and $388 \mathrm{~kg} / \mathrm{hm}^{2}$, total sugar was highest for $688 \mathrm{~mm}$ and $3362 \mathrm{~kg} / \mathrm{hm}^{2}$; vitamin C was highest for $622 \mathrm{~mm}$ and $376 \mathrm{~kg} / \mathrm{hm}^{2}$; PNP was greatest for $822 \mathrm{~mm}$ and $257 \mathrm{~kg} / \mathrm{hm}^{2}$; and WUE was highest for $580 \mathrm{~mm}$ and $388 \mathrm{~kg} / \mathrm{hm}^{2}$ (Table 7). 
Table 7. Irrigation corresponding to maximum yield, net benefit, total sugar, vitamin C, partial productivity of nitrogen fertilizer (PNP), and water use efficiency (WUE).

\begin{tabular}{cccc}
\hline Dependent Variable & $\begin{array}{c}\text { Maximum Dependent } \\
\text { Variable }\end{array}$ & $\begin{array}{c}\text { Irrigation Amount } \\
\mathbf{( m m})\end{array}$ & $\begin{array}{c}\text { Nitrogen Rate } \\
\mathbf{( k g . h m} \mathbf{~}^{\mathbf{2}} \mathbf{)}\end{array}$ \\
\hline Yield $\left(\mathrm{kg} / \mathrm{hm}^{2}\right)$ & 8901.5 & 700 & 340 \\
Net benefit $\left(\mathrm{RMB} / \mathrm{hm}^{2}\right)$ & 40467 & 745 & 388 \\
Total sugar $(\mathrm{g} / 100 \mathrm{~g})$ & 73.0 & 688 & 362 \\
Vitamin C $(\mathrm{mg} / 100 \mathrm{~g})$ & 118.0 & 622 & 376 \\
PNP $(\mathrm{kg} / \mathrm{kg})$ & 33.32 & 880 & 256.57 \\
WUE & 0.986 & 580 & 388 \\
\hline
\end{tabular}

Several indexes cannot all reach their maxima for the same inputs. The yield of total sugar, vitamin C, and WUE was close to the irrigation and fertilization area; however, PNP was very different to these indicators, and so it is not considered a comprehensive evaluation. Using the spatial analysis method, horizontal projection was carried out on the curved surface obtained from the above-mentioned index binary quadratic regression equations to obtain the relationships between irrigation nitrogen supply and relative yield, relative total sugar, and relative vitamins (Figure 6). The maxima of yield, net benefit, total sugar, vitamin, WUE, and PNP did not have the same optima of irrigation and fertilization amounts (Figure 6). The purpose of this study was to find the best comprehensive irrigation and nitrogen application rate, but the units of each treatment are different and so normalization processing was used for analysis. The spatial analysis method used $95 \%, 90 \%$, $85 \%, 80 \%$, and $75 \%$ of the above five indicators for evaluation, and showed that $95 \%$ of the acceptable areas of net benefits and $95 \%$ of the acceptable areas of yield and quality did not overlap. However, in $85 \%$ of the acceptable areas, there were overlapping areas that simultaneously satisfied several indicators, and the five indicators also had relatively close areas. The irrigation and nitrogen application intervals of $85 \%$ of the accepted regional maximum were about $600-628 \mathrm{~mm}$ and $360-368 \mathrm{~kg} / \mathrm{hm}^{2}$, respectively (Figure 7).

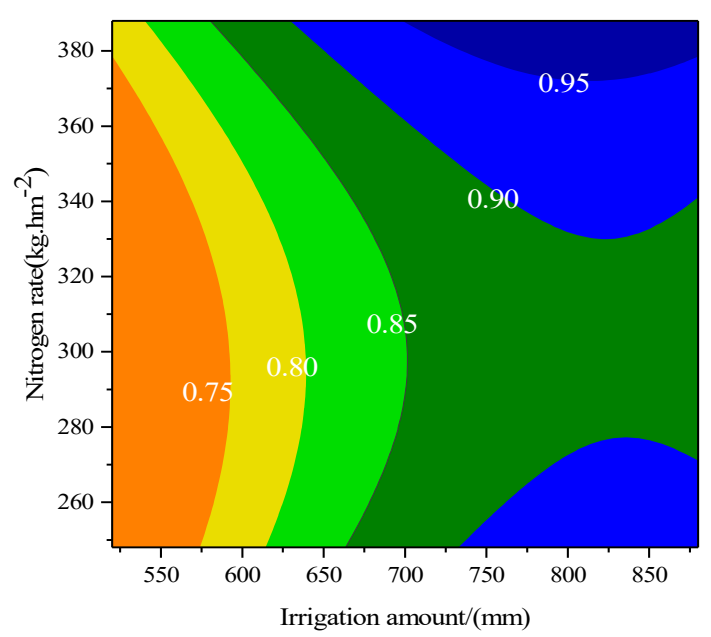

a. Relative economic benefits

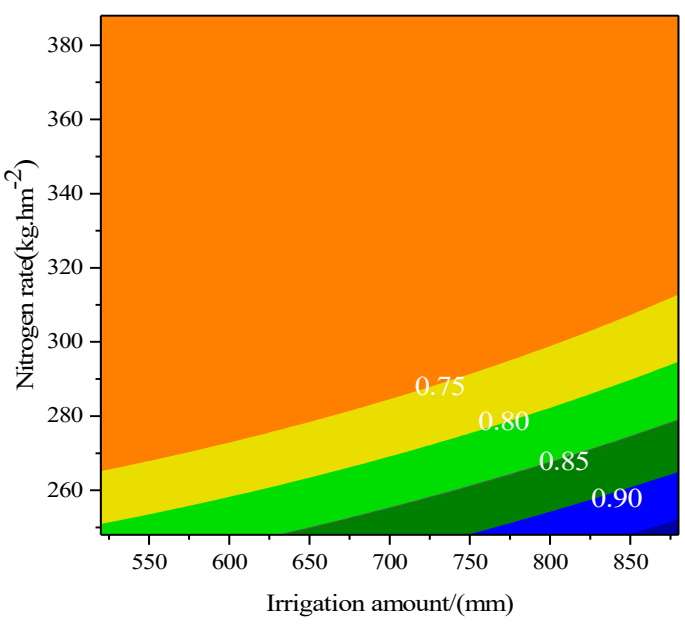

b. Partial productivity of relative nitrogen fertilizer

Figure 6. Cont. 

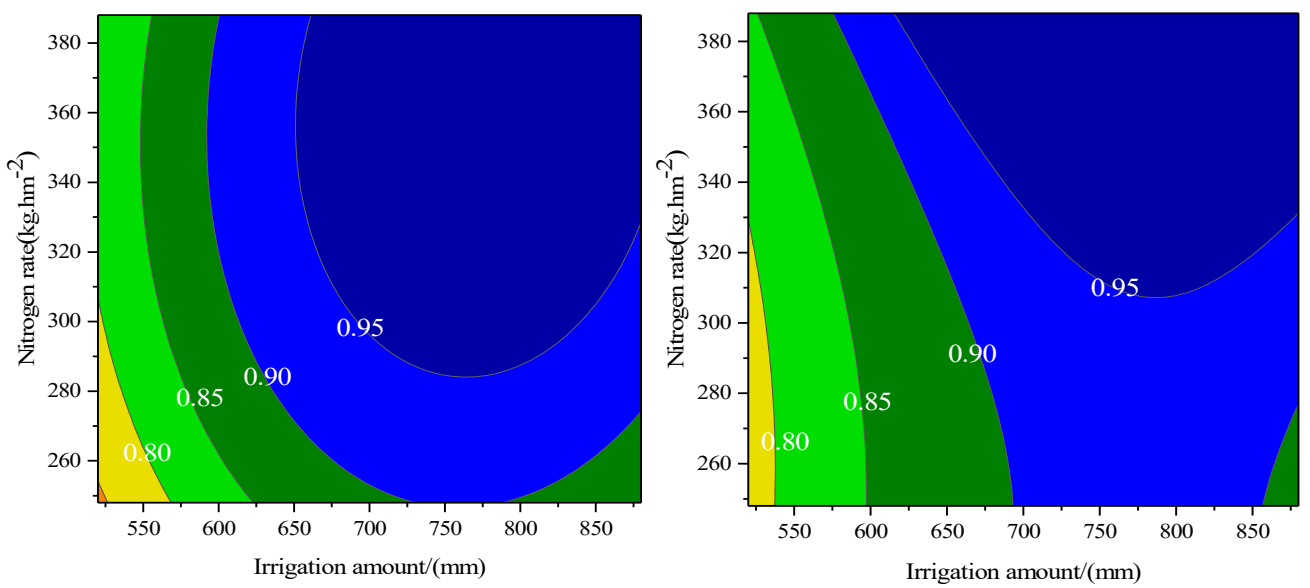

c. Relative total sugar

d. Relative yield

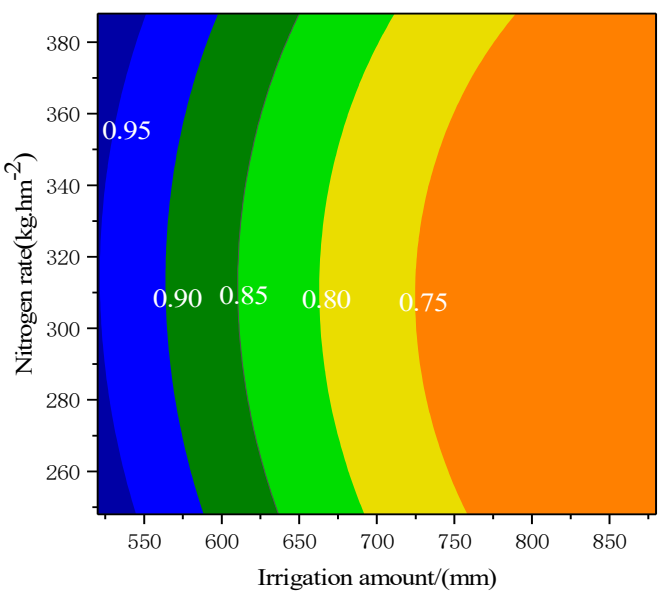

e. Relative water use efficiency

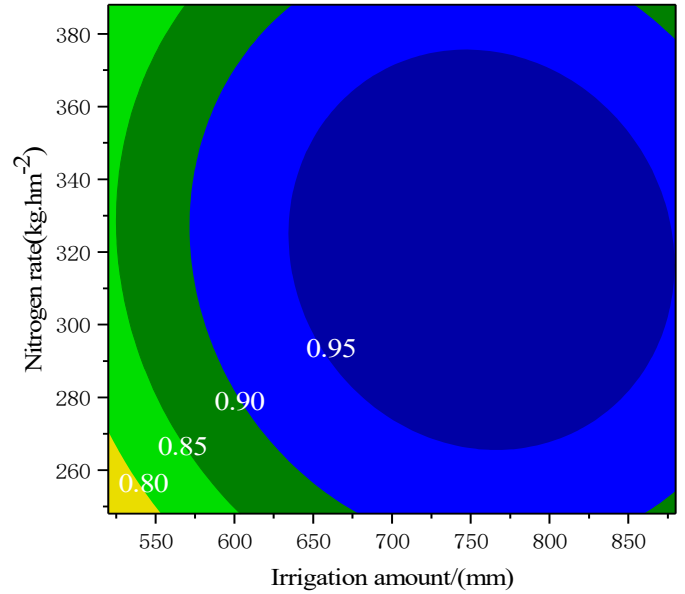

f. Relative vitamins

Figure 6. Relationships between water and nitrogen inputs and relative economic benefit, partial productivity of relative nitrogen fertilizer, relative total sugar, relative yield, relative water use efficiency, and relative vitamin C. Note: $0.95,0.9,0.85,0.8$, and 0.75 mean ratio of each index of its maximum value.

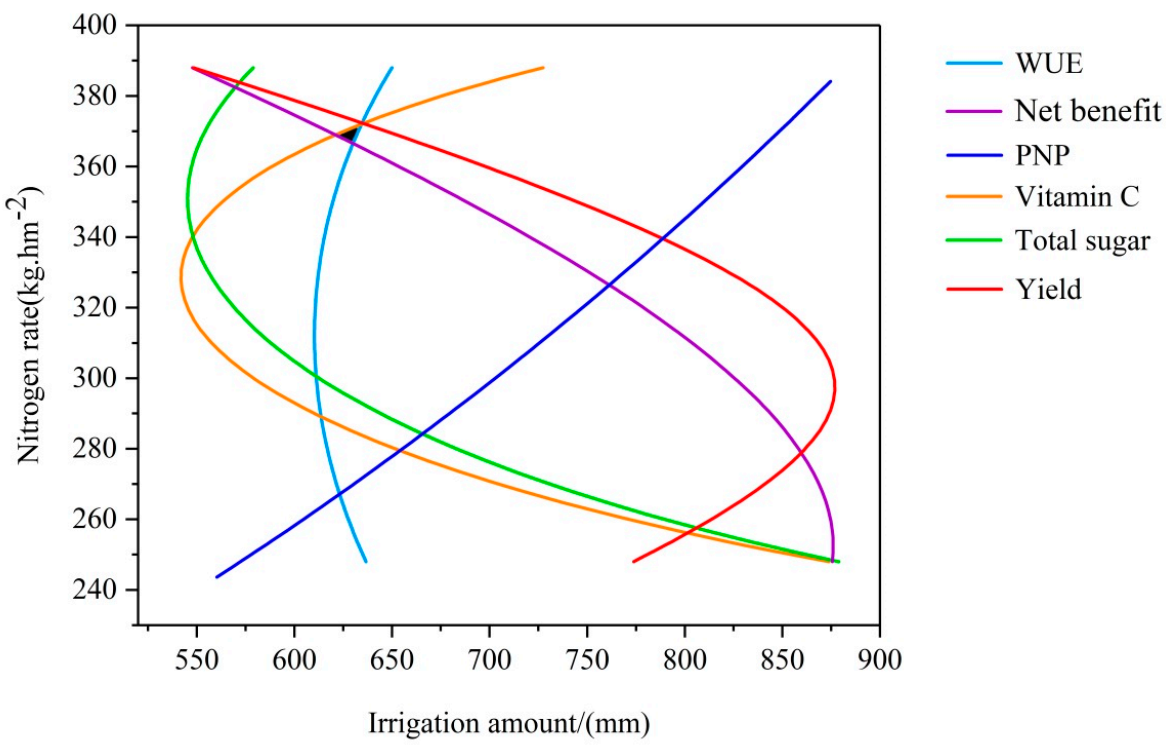

Figure 7. Comprehensive evaluation of yield, economic benefit, vitamin $C$, total sugar, yield, water use efficiency (WUE), and partial productivity of nitrogen fertilizer (PNP). 


\section{Discussion}

In this experiment, jujube roots were sampled in the horizontal and vertical directions, and the root weight and length densities at each sampling point were added to represent the total root characteristic value of the root system. The root length and weight densities of jujube were very significantly affected by the interaction of irrigation and nitrogen application (Table 3) $(p<0.01)$. In this experiment, within a certain irrigation range, the root length and weight densities of jujube increased with the increase of the nitrogen application rate. This is consistent with the findings of Liu Hongguang et al. [8] and others, who found that increasing the nitrogen supply level under low soil moisture conditions can significantly increase root dry weight and root volume and promote root penetration. There were significant linear positive relationships of root length and weight densities with yield (Figure 5). This shows that irrigation and nitrogen application played an important role in root growth of jujube and affected the yield. Appropriate application of water and nitrogen fertilizer improved WUE (Figure 4). WUE was affected by water quantity, but as nitrogen application decreased, WUE decreased-the nitrogen application had a significant effect on WUE. Under the same irrigation condition, within a certain range of nitrogen application, the increase in nitrogen application rate resulted in increased WUE. For low irrigation (W1) and high nitrogen (F3), WUE was at a maximum. PNP decreased with the increase in nitrogen application at the same irrigation level. For high irrigation (W3) and low nitrogen (F1), PNP was the largest. The irrigation improved the ability of crops to absorb nutrients and raised nitrogen use efficiency (Figure 6). Although fertilizer rate low nitrogen (F1) had higher productivity under different irrigation levels, it did not meet the production requirements, so medium nitrogen (F2) and high nitrogen (F3) were beneficial to yield and fertilizer utilization efficiency.

Output and quality are important indicators of economic benefits of jujube [16]. Water and nitrogen are important factors affecting the yield of red jujube. Crop yields differ under different water and nitrogen conditions. When water and nitrogen are insufficient, increasing the amount of irrigation and nitrogen application can improve the yield. When soil fertility is continuously increasing, the effect of water becomes greater, that is, "water promotes fertilizer and water transfers by fertilizer" [21]. However, there is a threshold reaction in water-nitrogen coupling-when lower than the threshold, increasing the water-nitrogen input has an obvious effect of increasing production. Above the threshold, the yield increase is not significant [22,23]. The irrigation amount and nitrogen rate at the maximum yield in this study were $700 \mathrm{~mm}$ and $340 \mathrm{~kg} / \mathrm{hm}^{2}$ (Table 4), respectively, differing from corresponding amounts of $651-806 \mathrm{~mm}$ and $708-810 \mathrm{~kg} / \mathrm{hm}^{2}$ obtained by Wang Zhenhua et al. [5] through parameter estimation and likelihood function combination method, and the irrigation quota and difference obtained by Liu Hongguang et al. [8]; this is likely owing to the different test sites. The results of Galindo et al. [24] showed that jujube trees grew best in the Mediterranean when the irrigation interval was $274-440 \mathrm{~mm}$. The conclusion of this study is different. The main reason is that our study area is located in the extreme arid area of Northwest China. During the growth period of jujube trees, the effective rainfall is very small and evaporation is very strong. Thus, we conclude that the optimum irrigation interval for jujube trees is 600-628 $\mathrm{mm}$. Ningbo Cui et al. [25] proposed that increasing the irrigation amount and nitrogen rate could improve the total sugar and vitamin $C$ contents of jujube; however, exceeding a certain limit would have the opposite effect, similar to conclusions drawn in our study. We used multiple regression and spatial analyses to comprehensively evaluate yield, quality, WUE, PNP, and other indicators, and the best irrigation and nitrogen application intervals $[16,26]$ were found in the $85 \%$ overlapping areas: irrigation amount of $600-628 \mathrm{~mm}$ and nitrogen rate of $360-368 \mathrm{~kg} / \mathrm{hm}^{2}$ (Figure 7). This irrigation and nitrogen application interval provides a basis for water and nitrogen management of jujube trees with high yield, quality, and efficiency. Thompson et al. [12] and Pierr et al. [15] used spatial analysis to evaluate the agronomic, economic, and environmental benefits of drip irrigation of watermelons and oilseeds, to obtain an appropriate irrigation interval. Thomas et al. [12-14] and others [16,26,27] also applied this method to comprehensively evaluate the agronomic, economic, and environmental benefits of cauliflower under subsurface drip irrigation and nitrogen application, and determined an appropriate combination scheme by looking for overlapping 
areas. This method can determine an expected value and find the optimal irrigation and nitrogen application interval through overlapping areas, which is feasible in production management and popularization and application.

\section{Conclusions}

(1) Under the drip irrigation conditions studied, the treatment W2F3 (irrigation amount $=700 \mathrm{~mm}$ and nitrogen rate $=388 \mathrm{~kg} / \mathrm{hm}^{2}$ ) allowed to obtain the maximum simultaneous yield, total sugar, and vitamin C of jujube, which were $8868 \mathrm{~kg} / \mathrm{hm}^{2}, 73.13 \mathrm{~g} / 100 \mathrm{~g}$, and $120.75 \mathrm{mg} / 100 \mathrm{~g}$, respectively. The treatment W1F3 (irrigation amount $=520 \mathrm{~mm}$ and nitrogen rate $=388 \mathrm{~kg} / \mathrm{hm}^{2}$ ) achieved the maximum WUE, which was $0.94 \mathrm{~kg} / \mathrm{m}^{3}$. The treatment W3F1 (irrigation amount $=880 \mathrm{~mm}$ and nitrogen rate $=248 \mathrm{~kg} / \mathrm{hm}^{2}$ ) achieved the maximum PNP, which was $35.75 \mathrm{~kg} / \mathrm{kg}$.

(2) Multiple regression and spatial analyses were used to obtain the interval where the yield, net benefit, total sugar, vitamin C, WUE, and PNP simultaneously reached maxima of $\geq 85 \%$ when the irrigation amount and nitrogen rate were $600-628 \mathrm{~mm}$ and $360-368 \mathrm{~kg} / \mathrm{hm}^{2}$, respectively, which was conducive to achieving high yield, efficiency, and quality production of jujube using drip fertigation.

Author Contributions: Conceptualization, H.L.; Methodology, E.L. and H.L.; Software, E.L.; Validation, E.L., X.L., P.G., and L.L.; Resources, H.L.; Data Curation, E.L. and H.L.; Writing-Original Draft Preparation, E.L.; Writing-Review \& Editing, H.L.; Visualization, E.L., X.L., L.L., and P.G.; Supervision, H.L. and X.H.; Project Administration, H.L. and X.H.; Funding Acquisition, H.L.

Funding: We acknowledge the financial support from the National Natural Science Foundation Program (U1803244) and the National Natural Science Foundation Program (51669029) and the National Key Research and Development Plan for the 13th Five-Year Plans (2016YFC0501406).

Acknowledgments: We thank the editors and anonymous reviewers for their fruitful comments. We also thank International Science Editing (http://www.internationalscienceediting.com) for editing this manuscript.

Conflicts of Interest: The authors declare no conflict of interest. The founding sponsors had no role in the design of the study; in the collection, analyses, or interpretation of data; in the writing of the manuscript; and in the decision to publish the results.

\section{References}

1. Wang, Y.; Li, Z.L.; Liu, X.H. Current Situation and Variety Selection of Jujube Industry in Xinjiang. Rural science \& thchnology. 2017, 9, 1002-6193.

2. Qi, L.Q. The Present Situation, Requirements and Development Trends of Xinjiang Red Date Industry. Xinjiang Agric. 2010, 47, 1001-4330.

3. Ren, Y.Z.; Wang, S.X.; Xie, L.; Dong, X.G. Effects of irrigation methods on water use efficiency and fruit quality of jujube in arid area. Trans. Chin. Soc. Agric. Eng. 2012, 28, 1002-6819.

4. Pei, Q.B.; Liu, W.J.; Zhang, J.F.; Wang, H.W. Movement and numerical simulation of soil water solute migration under multipoint drip irrigation in red soil. Trans. Chin. Soc. Agric. Mach. 2017, 48, 1000-1298.

5. Wang, Z.H.; Bian, Q.Y.; Zhang, J.Z.; Zhou, B. Optimized water and fertilizer management of mature jujube in Xinjiang arid area using drip irrigation. Water 2018, 10, 1467. [CrossRef]

6. Wang, Z.H.; Bian, Q.Y.; Li, W.H.; Li, Z.Y. Suitable water and fertilizer amount for mature jujube with drip-irrigation under fertigation in southern Xinjiang sandy area. Trans. Chin. Soc. Agric. Eng. 2018, 34, 96-104.

7. Shi, P.J.; Liu, H.G.; He, X.L.; Lu, H.T.; Ye, J.W. The influence of water and fertilizer coupling on physiological change andyield of dwarf dense planting jujube under drip irrigation. J. Nucl. Agric. Sci. 2018, 32, 177-187.

8. Liu, H.G.; He, X.L.; Li, J.; Li, F.D.; Gong, P.; Zhang, J. Effects of water-fertilizer coupling on root distribution and yield of Chinese Jujube trees in Xinjiang. Int. J. Agric. Biol. Eng. 2017, 10, 103-114.

9. Liu, X.L.; Ma, L.H.; Wang, Y.K. Distribution characteristic of fine root and soil water of densely jujube plantation with drip irrigation. Trans. Chin. Soc. Agric. Eng. 2013, 29, 63-71.

10. Wang, Q.X.; Zhang, J.H.; Zhang, Y.X. Effects of water and fertilizer coupling on soil nutrients and fruit quality in pear orchard. China Fruits 2013, 4, 18-23. 
11. Zhou, H.M.; Zhang, F.C.; Roger, K.L.; Wu, L.F.; Fan, J.L.; Xiang, Y.Z. Effects of water and fertilizer coupling on yield, fruit quality and water and fertilizer use efficiency of young apple tree. Trans. Chin. Soc. Agric. Mach. 2015, 46, 173-183.

12. Thompson, T.L.; Doerge, T.A. Nitrogen and water interactions in subsurface trickle-irrigated leaf lettuce.2. Agronomic, economic, and environmental outcomes. Soil Sci. Soc. Am. J. 1996, 60, 168-173. [CrossRef]

13. Thompson, T.L.; Doerge, T.A.; Godin, R.E. Nitrogen and water interactions in subsurface drip-irrigated cauliflower: II. Agronomic, economic, and environmental outcomes. Soil Sci. Soc. Am. J. 2000, 64, 412-418. [CrossRef]

14. Thompson, T.L.; Doerge, T.A.; Godin, R.E. Subsurface drip irrigation and fertigation of broccoli: II. Agronomic, economic, and environmental outcomes. Soil Sci. Soc. Am. J. 2002, 66, 178-185. [CrossRef]

15. Pier, J.W.; Doerge, T.A. Concurrent evaluation of agronomic, economic, and environmental aspects of trickle-irrigated watermelon production. J. Environ. Qual. 1995, 24, 79-86. [CrossRef]

16. Xing, Y.Y.; Zhang, F.C.; Wu, L.F.; Fan, J.L.; Zhang, Y.; Li, J. Determination of optimal amount of irrigation and fertilizer under drip fertigated system based on tomato yield, quality, water and fertilizer use efficiency. Trans. Chin. Soc. Agric. Eng. 2015, 31, 110-121.

17. Wang, B.J.; Zhang, W.; Ahanbieke, P.; Gan, Y.W.; Xu, W.L.; Li, L.H.; Christie, P.; Li, L. Interspecific interactions alter root length density, root diameter and specific root length in jujube/wheat agroforestry systems. Agrofor. Syst. 2014, 88, 835-850. [CrossRef]

18. Jinan Fruit Research Institute All China Federation of Supply and Marketing Cooperatives. Dried red Jujube. General Administration of Quality Supervision, Inspection and Quarantine of the People's Republic of China; GB/T 5835-2009; Jinan Fruit Research Institute All China Federation of Supply and Marketing Cooperatives: Beijing, China, 2009.

19. Hu, Y. Optimized Regulated Deficit Irrigation Mode and Crop Coefficient of Drip Irrigation Jujube in Loess Plateau. Ph.D. Thesis, Northwest A\&F University, Xianyang, China, 2013.

20. Hu, S.; Wang, X. Effects of fertilization on biological properties and water and fertilizer use efficiency of maize in black soil region of northeast China. J. Soil Water Conserv. 2017, 31, 219-226.

21. Kuscu, H.; Turhan, A.; Ozmen, N.; Aydinol, P.; Demir, A.O. Optimizing levels of water and nitrogen applied through drip irrigation for yield, quality, and water productivity of processing tomato (Lycopersicon esculentum Mill.). Hortic. Environ. Biotechnol. 2014, 55, 103-114. [CrossRef]

22. Wu, H.Q.; Du, S.Y.; Zhang, Y.L.; An, J.; Zou, H.T.; Zhang, Y.L.; Yu, N. Effects of irrigation and nitrogen fertilization on greenhouse soil organic nitrogen fractions and soil-soluble nitrogen pools. Agric. Water Manag. 2019, 216, 415-424. [CrossRef]

23. Liang, Z.; Zhang, J.F.; Jing, R.; Zou, Y.X. Influence of Fertilization Modes and Fertilization Levels under Drip Irrigation on Fruit Yield, Quality and Nutrient Use of Chinese Jujube. Xinjiang Agric. Sci. 2016, 53, 1444-1452.

24. Galindo, A.; Cruz, Z.N.; Rodriguez, P.; Collado-Gonzalez, J.; Corell, M.; Memmi, H.; Moreno, F.; Moriana, A.; Torrecillas, A.; Perez-Lopez, D. Jujube fruit water relations at fruit maturation in response to water deficits. Agric. Water Manag. 2016, 164, 110-117. [CrossRef]

25. Cui, N.B.; Du, T.S.; Kang, S.Z.; Li, F.S.; Zhang, J.H.; Wang, M.X.; Li, Z.J. Regulated deficit irrigation improved fruit quality and water use efficiency of pear-jujube trees. Agric. Water Manag. 2008, 95, 489-497. [CrossRef]

26. Bai, T.C.; Zhang, N.N.; Chen, Y.Q.; Mercatoris, B. Assessing the performance of the wofost model in Simulating jujube fruit Tree growth under different irrigation regimes. Sustainability 2019, 11, 1466. [CrossRef]

27. Yang, H.; Cao, H.X.; Li, H.Z.; Guo, L.J.; Du, Y.D. An investigation on optimal irrigation and nitrogen rates of greenhouse tomato based on spatial analysis forhigh yield and quality. Sci. Agric. Sin. 2016, 49, 896-905.

(C) 2019 by the authors. Licensee MDPI, Basel, Switzerland. This article is an open access article distributed under the terms and conditions of the Creative Commons Attribution (CC BY) license (http://creativecommons.org/licenses/by/4.0/). 